\title{
Synthesis and characterization of biochar from peel and seed of jackfruit plant waste for the adsorption of copper metal ion from water
}

\begin{abstract}
In this work, jackfruit peel and seeds are utilized to synthesized the biochar for the removal of copper metal ions from water. The synthesized jackfruit peel and seeds were carbonized at $500 \mathrm{oC}$ for $2 \mathrm{~h}$ under air atmosphere flow. The JPB and JSB were characterized by the use of different characterization techniques such as XRD, BET, FTIR, SEM and CHNS to study it's physic-chemical properties. The synthesized biochar samples were tested for the removal of $\mathrm{Cu}$ metals ion from water and recorded excellent adsorption capacity of $99.84 \%$ by JPB adsorbent at optimize adsorption conditions of $45 \mathrm{oC}$ adsorption temperature, $7 \mathrm{pH}$, 24 hours contact time and $100 \mathrm{ppm}$ of metal solution concentration. The lowest adsorption capacity of $79.60 \%$ was recorded by JSB adsorbent under the optimized parameters of $25 \mathrm{oC}$ temperature, $7 \mathrm{pH}, 24$ hours contact time and $40 \mathrm{ppm}$ metal ion concentration. The results demonstrated that, jackfruit based biochar would be an excellent adsorbent for heavy metals from water.
\end{abstract}

Keyword: Adsorption; Heavy metals; Jackfruit peel; Jackfruit seed; Characterization 